\title{
The potential for induction of the expression of bone morphogenetic protein- 7 and alkaline phosphatase in postextraction tooth sockets using a combination of mangosteen peel extract and DFDBBX
}

\author{
Utari Kresnoadi $^{1 *}$, Diva Amelia Ruslianda ${ }^{2}$, Harry Laksono ${ }^{1}$ \\ ${ }^{1}$ Department of Prosthodontics, Faculty of Dental Medicine, Universitas Airlangga, Surabaya, Indonesia. \\ ${ }^{2}$ Resident, Department of Prosthodontics, Faculty of Dental Medicine, Universitas Airlangga, Surabaya, Indonesia.
}

\begin{tabular}{|c|c|}
\hline ARTICLE INFO & ABSTRACT \\
\hline $\begin{array}{l}\text { Received on: 02/02/2021 } \\
\text { Accepted on: 09/10/2021 } \\
\text { Available Online: } 05 / 02 / 2022\end{array}$ & $\begin{array}{l}\text { This study was determined to verify that the combination of DFDBBX and mangosteen peel extract can increase the } \\
\text { expression of bone morphogenetic protein-7 (BMP-7) and alkaline phosphatase (ALP) in tooth sockets on days } 7 \\
\text { and } 30 \text { after extraction. The central lower incisors of Cavia cobaya were extracted using a needle holder, after which } \\
\text { polyethylene glycol (PEG), DFDBBX + PEG, mangosteen peel extract + PEG, and a combination of DFDBBX + }\end{array}$ \\
\hline $\begin{array}{l}\text { Key words: } \\
\text { DFDBBX, Garcinia } \\
\text { mangostana, BMP-7, ALP, } \\
\text { medicine. }\end{array}$ & $\begin{array}{l}\text { an immunohistochemical examination of the expression of B MP-7 and ALP was performed. Statistical analysis by } \\
\text { means of the analysis of variance indicated that each group was significantly different. The combination group showed } \\
\text { the highest expression of BMP- } 7 \text { and ALP on days } 7 \text { and } 30 \text {, followed by the mangosteen peel extract group. A } \\
\text { combination of DFDBBX and mangosteen peel extract } 2 \% \text { was applied to the C. cobaya tooth socket after extraction } \\
\text { which increased the expression of BMP- } 7 \text { and ALP on days } 7 \text { and } 30 \text {. }\end{array}$ \\
\hline
\end{tabular}

\section{INTRODUCTION}

Bone resorption after tooth extraction occurs in two phases and impairs the prognosis of prosthodontic treatment. Postextraction resorption of the alveolar ridge creates a defect that potentially complicates implant placement and denture fabrication, while also increasing the need for bone augmentation that could necessitate prolonged treatment (Jamjoom and Cohen, 2015). Resorption of the alveolar bone occurs over a period of more than 12 months; $2 / 3$ of the total resorption happens during the first 3 months after extraction (Kyun Kim et al., 2017; Pagni et al., 2012b). The initial phase of alveolar bone resorption is the resorption of the bundle bone making up Sharpey's fibers which are replaced by new immature woven bone. Mature lamellar bone replaces immature woven bone and fills the socket together

\section{*Corresponding Author}

Utari Kresnoadi, Department of Prosthodontics, Faculty of Dental Medicine, Universitas Airlangga, Surabaya, Indonesia.E-mail: utari-k@fkg.unair.ac.id with mature bone. During the second phase, the surface of the alveolar bone periosteal undergoes remodeling through resorption by osteoclast and formation by osteoblast, resulting in ridge contraction both horizontally and vertically (Jamjoom and Cohen, 2015). This second phase of resorption can be inhibited by the socket grafting method using bone material substitutes or bone graft (Pagni et al., 2012a, 2012b).

DFDBBX is one xenograft often employed during socket preservation because of its osteoinductive potential resulting from the exposed bone morphogenetic protein (BMP) after being demineralized and freeze-dried. Garcinia mangostana is occasionally used in medical procedures due to its antiinflammatory and antioxidant properties. The research conducted by Kresnoadi et al. (2017) shows the potency of a combination of DFDBBX and mangosteen peel extract in reducing the osteoclast cell count in Cavia cobaya on days 7 and 30 after tooth extraction. The role of the BMP-7 expressed during bone healing is essential to the induction and differentiation of osteoblast (Giorgetti et al., 2010). A study conducted by Dunn et al. (2008) indicated excellent 
bone forming in the implant defect of alveolar bone through the application of BMP-7 in competent experimental animal subjects. Osteoblast secreted alkaline phosphatase (ALP) as its phenotype marker which induces mineralization of the bone matrix and osteogenic differentiation. A study on bone healing confirmed that the circulating ALP increased after surgery, followed by a gradual decline in its level during the normal healing process (Giorgetti et al., 2010). This study aimed to verify that a combination of DFDBBX and mangosteen peel extract could increase the expression of BMP-7 and ALP in tooth sockets on days 7 and 30 after extraction.

\section{MATERIALS AND METHODS}

\section{Ethical clearance}

This study constitutes experimental research with randomized factorial design (true experimental design). An ethical clearance certificate was issued by the Health Research Ethical Clearance Commission according to seven WHO 2011 with number 420/HRECC.FODM/IX/2020.

\section{Subject preparation}

The research subjects consisted of healthy, active, male C. cobaya 300-350 g in weight and aged 3-3.5 months, demonstrating a normal appetite and body temperature, with the normal function of the five senses, without injuries or deformities to the limbs and skin, and without a limp.

\section{materials and instrument preparation}

The materials used in this experiment consisted of mangosteen peel extract, distilled sterile aquades, DFDBBX produced by BATAN with $60 \mathrm{mesh} / 250$ microns, polyethylene glycol (PEG) suspension 400 and 4000, absolute alcohol 90\%, $80 \%, 70 \%, 50 \%$, and $30 \%$, formalin buffer, ethanol $96 \%$, paraffin liquid, xylol liquid, ethylenediaminetetraacetic acid (EDTA), monoclonal antibody BMP-7 and ALP (Santa Cruz ${ }^{\circledR}$ ), and immune staining kit reagent (Novocastra-Leica $\left.{ }^{\circledR}\right)$. Mangosteen peel extract was obtained and mixed with DFDBBX, producing a composition of $0.5 \mathrm{~g}$ mangosteen peel extract, $0.5 \mathrm{~g}$ DFDBBX, and 2.4 g PEG $4000+$ PEG 400, which resulted in a $2 \%$ active compound of the concentration (Kresnoadi et al., 2018).

\section{Extraction of $C$. cobaya teeth and application of DFDBBX and mangosteen peel extract}

The research subjects (C. cobaya) were divided into four groups, each consisting of seven subjects: control group of $C$. cobaya whose tooth sockets were treated with PEG, P1 group of $C$. cobaya whose tooth sockets were treated with DFDBBX + PEG, P2 group of $C$. cobaya whose tooth sockets were treated with mangosteen peel extract, and P3 group of $C$. cobaya whose tooth sockets were treated with a combination of DFDBBX + mangosteen peel extract + PEG. The C. cobaya were anesthetized using i.v. ketamin $0.2 \mathrm{cc} / 300 \mathrm{~g}$ body weight and their left lower central incisors extracted with a needle holder (Kresnoadi et al., 2018). After extraction, the sockets were filled with PEG, DFDBBX + PEG, mangosteen peel extract + PEG, and a combination of DFDBBX + mangosteen peel extract + PEG according to the group to which the subject belonged. On days 7 and 30, the C. cobaya were sacrificed, with the mandibles of the subjects being subsequently cut and decalcified with EDTA for 3 months to enable it to be easily sliced from paraffin block.

\section{Paraffin block and slides preparation}

A paraffin block was produced by a sequence of steps including fixation using formaldehyde $10 \%$, hydration for 60 minutes using alcohol at a range of concentrations $(30 \%, 50 \%$, $70 \%, 80 \%, 90 \%$, and absolute), cleaning using xylol which was performed twice for 60 minutes on each occasion, infiltration using soft paraffin for 60 minutes at a temperature of $48^{\circ} \mathrm{C}$, and at the final stage, blocking in hard paraffin. Slide preparation was performed by slicing the paraffin block using a rotary microtome to produce $4 \mu \mathrm{m}$ thick sections of tissue which were subsequently placed on the glass object and soaked in xylol twice for 5 minutes on each occasion. Any residual xylol was eliminated by means of rehydration using various concentrations of alcohol (absolute, $90 \%, 80 \%, 70 \%, 50 \%$, and $30 \%$ ) for 5 minutes and washing with $\mathrm{H}_{2} \mathrm{O}$ for a further 5 minutes.

\section{Immunohistochemistry examination}

After the slides of the tissues had been obtained, immunohistochemistry examination was performed by washing the slide with Phosphate-buffered saline (PBS) $\mathrm{pH} 7.4$ for 5 minutes, endogenous peroxide blocking using $3 \% \mathrm{H}_{2} \mathrm{O}_{2}$ for 20 minutes, unspecific protein blocking using 5\% PBS containing $0.25 \%$ Triton X-100, incubation with monoclonal antibody BMP7 and ALP for 60 minutes, incubation with anti-rabbit horseradish peroxidase (HRP) conjugated for 40 minutes, incubation with diaminobenzidine, incubation with Mayer's hematoxylin and counterstaining, and, finally, tissue mounting and examination using a light microscope to determine the expression of BMP-7 and ALP in osteoblast cells.

\section{Statistical analysis}

Statistical analysis was performed using the Kolmogorov-Smirnov test to quantify the homogeneity and normality of the data, which was then followed by the analysis of variance (ANOVA) test and Tukey honestly significant difference (HSD) test in order to identify any significant differences in the expression of BMP-7 and ALP between each group.

\section{Results}

The normality and homogeneity tests performed show that the data were normally and homogeneously distributed $(p>0.05)$, two results qualifying the data for the ANOVA test. This test showed that there are significant differences between the expression of BMP-7 and ALP in each group $(p<0.05)$; the analysis was continued with the Tukey HSD test conducted to identify the differences between each group. The result of this test showed that the expression of BMP-7 and ALP of the control group on days 7 and 30 differed significantly from those of the P1 group treated with DFDBBX, the P2 group treated with mangosteen peel extract, and the P3 group treated with a combination of DFDBBX and mangosteen peel extract. However, the expression of BMP-7 and ALP of group P1 on day 30 was not significantly different from that of the control group. The lowest mean value of the expression of BMP-7 on days 7 and 30 was found in the control group, while 
the highest mean value was found in the P3 group treated with a combination of DFDBBX and mangosteen peel extract (Fig. 1-6).

\section{DISCUSSION}

Postextraction bone resorption creates defects in the alveolar bone which leads to the impairment of prognosis in prosthodontic treatment. Socket grafting represents one socket preservation method performed following a tooth extraction, intended to preserve and maintain the volume of alveolar bone by filling the tooth socket with bone material substitute (Paknejad et al., 2017). The bone material subtitute used in this research is DFDBBX, manufactured by Pusat Aplikasi Isotop dan Radiasi Badan Tenaga Nuklir Nasional. DFDBBX was demineralized and freeze-dried to increase its osteoinductive potential by exposing the BMP it contains. Bone graft constitutes an essential element within the socket preservation method because it provides support for the host cells and extracellular matrix. It is necessary for the bone healing process, even though the study conducted by Venkataraman et al. (2015) confirmed the integration of the graft with the tissue through both cellular and chemical phase activities. Moreover, the filling of the pores and interspace of the xenograft from the bone only occurred during week 12 , so it is necessary to add certain materials to intensify the bone-forming process on the graft (Titsinides et al., 2019; Venkataraman et al., 2015). The results of this study show that there were significant differences in the expression of BMP-7 and ALP in the control group compared to the other groups with the exception of the P1 group treated with DFDBBX on day 30. However, there were no significant differences between the control group and the P1 group. The expression of BMP-7 and ALP in the P1 group on day 7 was significantly higher than that of the control group. This might be caused by the properties of DFDBBX which are more similar to the structure of cancellous bone in humans when compared to allograft and synthesis graft. The particle size is approximately $250-1,000$ $\mu \mathrm{m}$ which is the recommended size for a bone graft. Moreover, the demineralized and freeze-drying process in manufacturing
DFDBBX increased its osteoinductive potential by exposing the BMP in DFDBBX to enhanced differentiation of mesenchymal cells to osteoblast cells and enhanced expression of BMP-7 in osteoblast cells. The expression of ALP in osteoblast on day 7 also increased and was significantly different from the control group, as the number of osteoblast cells in the group treated with DFDBBX in the study conducted by Azhar et al. (2017) proliferated (Azhar et al., 2018). The expression of BMP-7 and ALP on day 30 was not significantly different compared to that of the control group since the osteoinductive properties of BMP in DFDBBX were unstable and affected by its carrier, temperature, $\mathrm{pH}$, and other factors. Hence, the effectiveness of the osteoinductive properties of DFDBBX decreased over time and the expression of BMP-7 and ALP by osteoblast cells on day 30 was not significantly higher than that of the control group (Bialy et al., 2017).

The expression of BMP-7 and ALP on days 7 and 30 in the P2 group treated with mangosteen peel extract was significantly higher than that in the control group. Mangosteen peel extract contains isogarcinol with calcineurin as an enzyme target. Fu et al. (2014) defined the inhibition by isogarcinol in mangosteen peel extract of the expression of nuclear factor kappa-light-chain-enhancer of activated B cells (NF- $\kappa \mathrm{B})$ through the inhibition of calcineurin as an activator of a transcription factor for inflammatory cytokine [Interleukin (IL)-6, IL-1 $\beta$, and Tumor necrosis factor alpha (TNF- $\alpha)$ ] and gene inflammatory inducible enzyme (iNos and COX-2). Moreover, the xanthone $(\alpha$-mangostin and $\gamma$-mangostin) content of mangosteen peel extract also contributed to its anti-inflammatory properties since it inhibits the expression of TNF- $\alpha$ and IL-1 (Azhar et al., 2018). Furthermore, mangosteen peel extract inhibits the expression of TNF- $\alpha$ produced by the inflammatory response after tooth extraction; TNF- $\alpha$ prevents the differentiation of mesenchymal stem cells to osteoblast and osteoblastogenesis or preosteoblast to osteoblast through Wnt pathway or by activating Smurf to impede the BMP-2 pathway (Osta et al., 2014). Those active compounds of mangosteen peel extract reduced the expression of NF- $\mathrm{KB}$ and

\section{Mean Value and Standard Deviation of Expression of BMP-7}

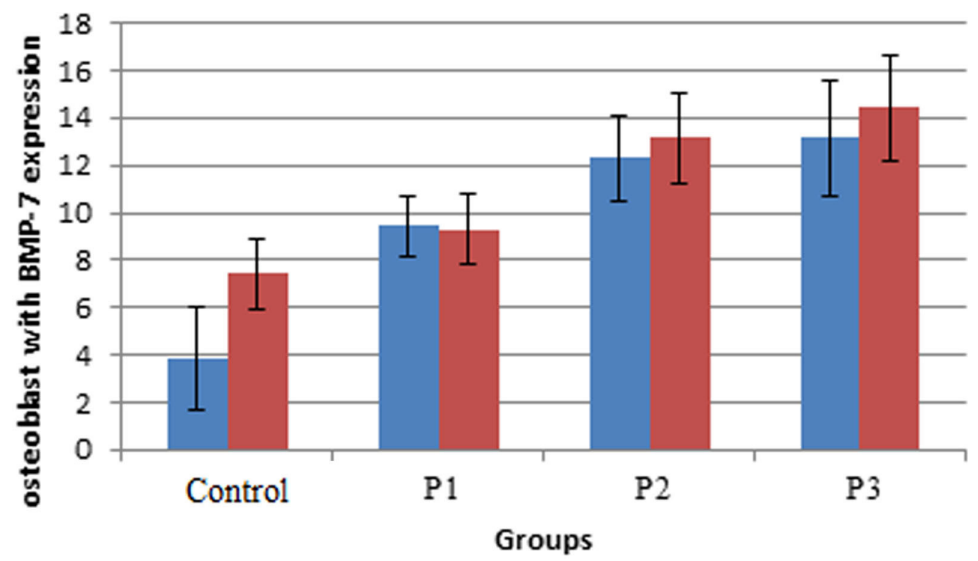

\section{- Days 7}

- Days 30

$\mathrm{P} 1=\mathrm{DFDBBX}+\mathrm{PEG}$

P2 = Mangosteen peel extract + PEG

P3 = DFDBBX + Mangosteen peel ex tract + PEG

Figure 1. Mean value and standard deviation of the expression of BMP-7 on days 7 and 30 . 

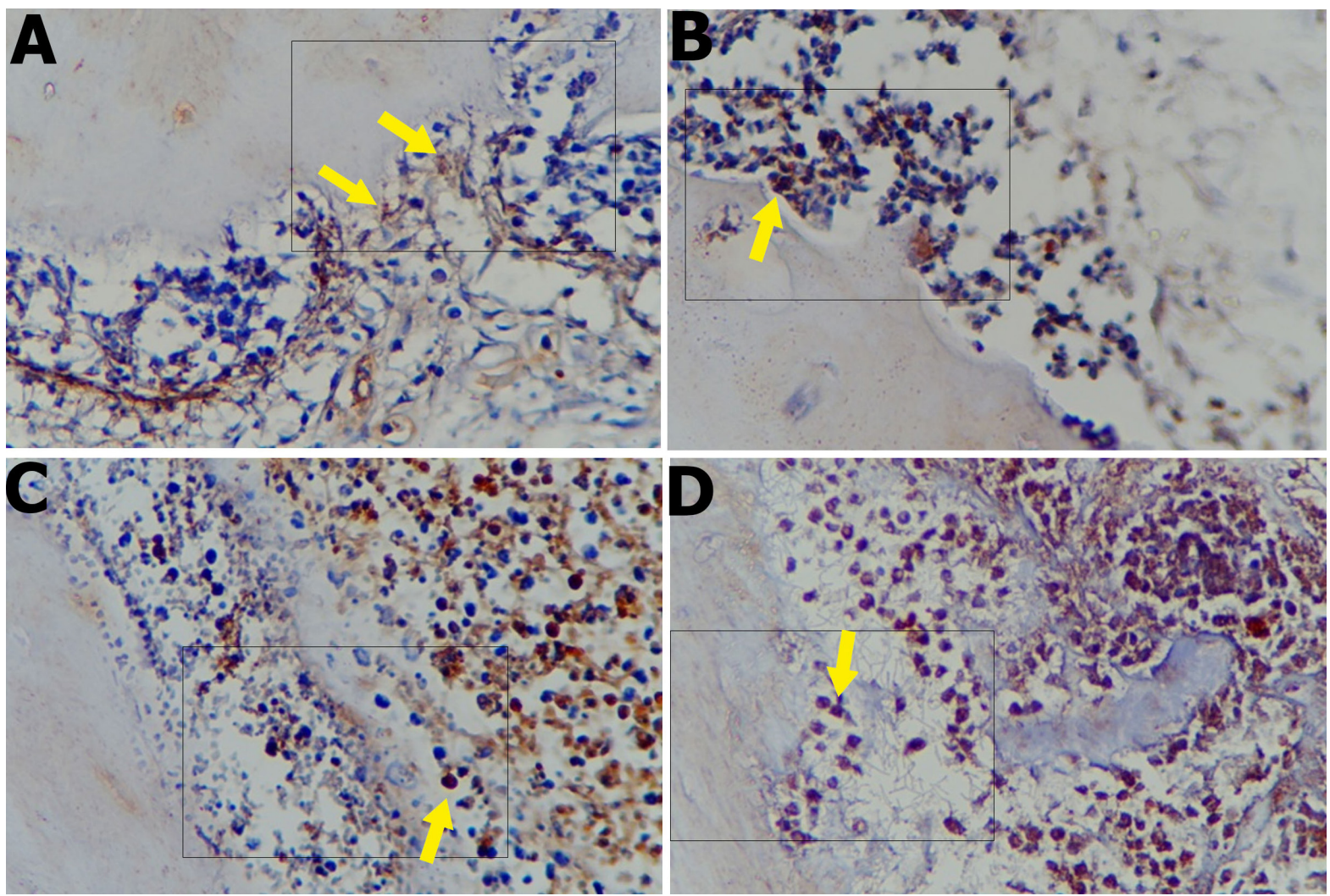

Figure 2. The expression of BMP-7 on day 7 of (a) control group, (b) P1 group, (c) P2 group, and (d) P3 group was observed using a light microscope at 400× magnification. Osteoblast cells are indicated by an arrow showing the expression of BMP-7.
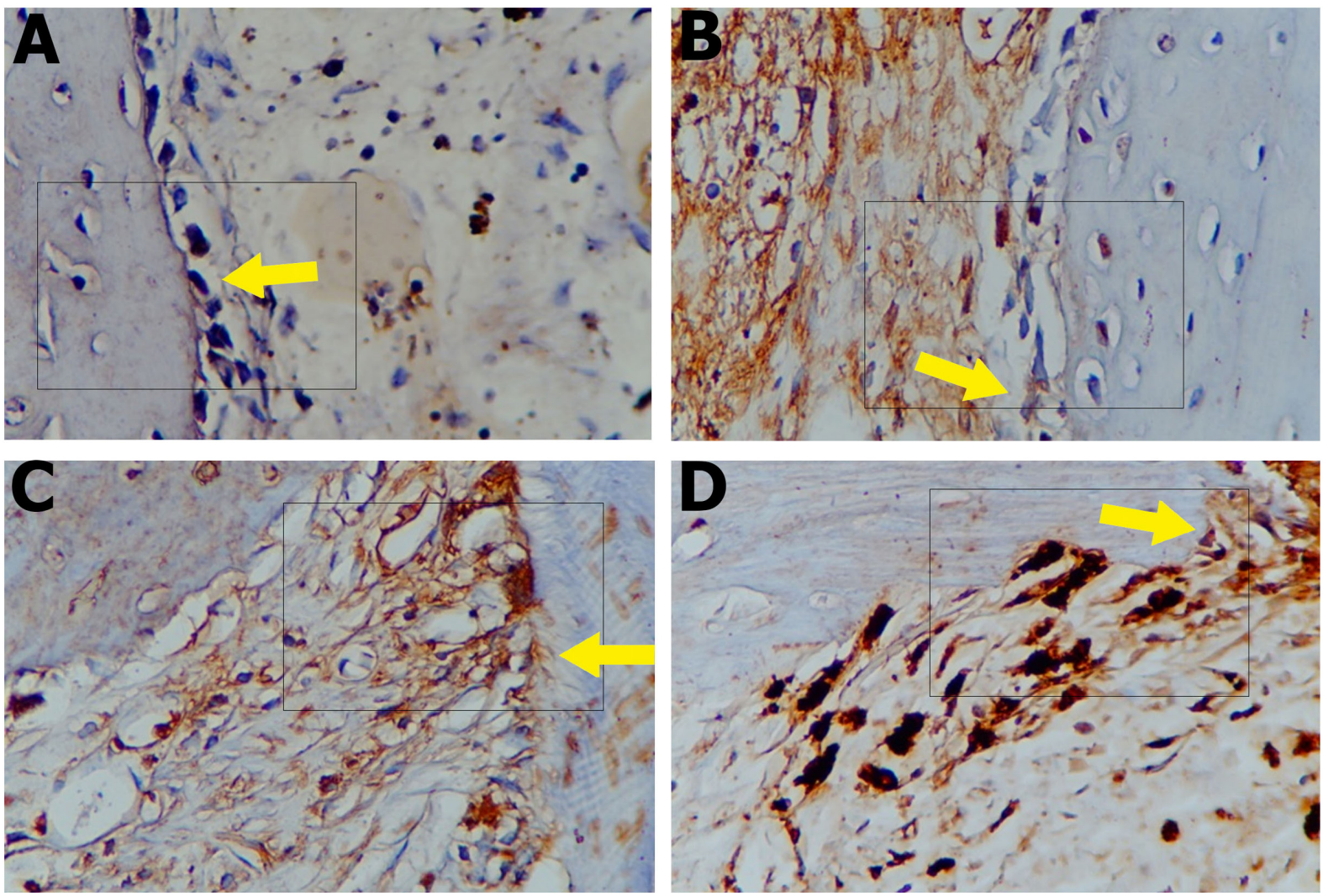

Figure 3. The expression of BMP-7 on day 30 of (a) control group, (b) P1 group, (c) P2 group, and (d) P3 group was observed using a light microscope at 400× magnification. Osteoblast cells are indicated by an arrow showing the expression of BMP-7. 


\section{Mean Value and Standard Deviation of Expression of ALP}

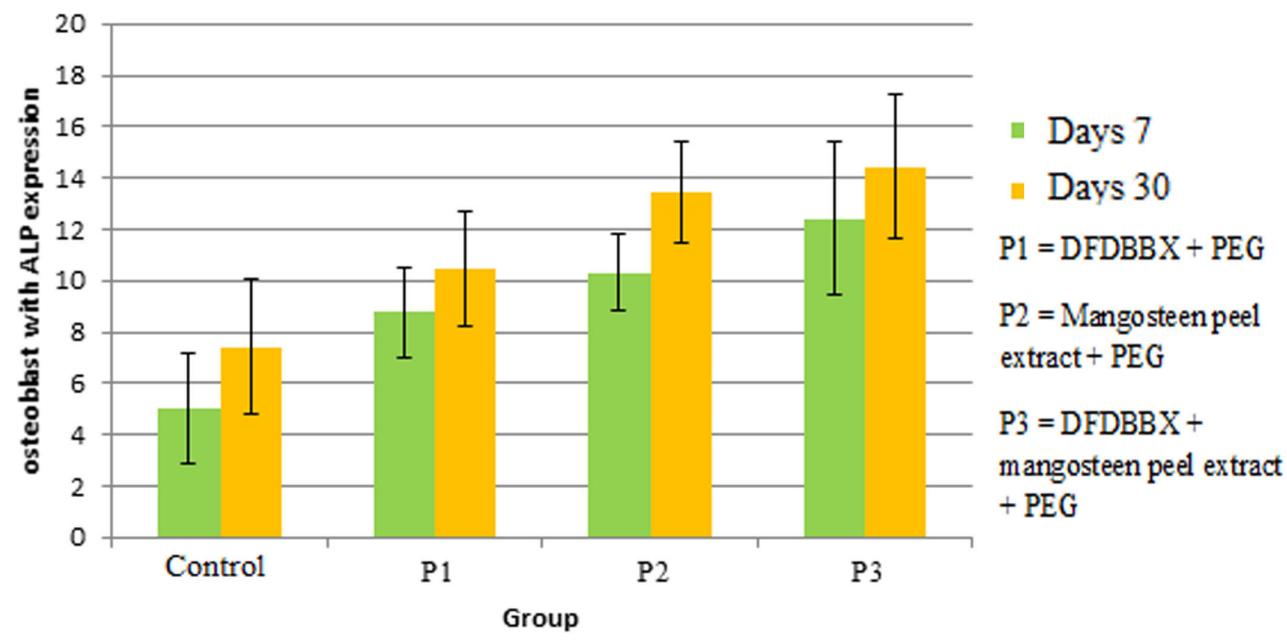

Figure 4. Mean value and standard deviation of the expression of BMP-7 on days 7 and 30.

IL-1 $\beta$ as confirmed by research conducted by Kresnoadi et al. (2017) and Azhar et al. (2018). Therefore, mangosteen peel extract can prevent the impairment of osteoblast differentiation by NF$\kappa \mathrm{B}, \mathrm{TNF}-\alpha$, and IL- $1 \beta$ and then increase the number of osteoblast cells as shown in the study conducted by Kresnoadi et al. (2017). As the number of osteoblast cells increased, the expression of BMP-7 which is essential for the induction and differentiation of osteoblast also increased. BMP-7 induced the ossification process by recruiting mesenchymal cells around the tissue to differentiate to osteoblast through chemotaxis. The expression of ALP also increased as a result since ALP is expressed by osteoblast as a biomarker of osteoblast differentiation to form osteoid and mineralization of bone matrix (Giorgetti et al., 2010; Seppänenkaijansinkko, 2019). This finding was supported by the results of research conducted by Lim et al. (2020) on human osteoblast-like cell lines that showed an increase in ALP activity on days 7 to 14 in the group treated with mangosteen peel extract compared to the negative control group. Xanthone in mangosteen peel extract initiates antioxidant activity essential to transforming the free radicals in order to reduce its reactivity and shorten the transition from the inflammation phase to the healing phase (Putri et al., 2017). Reactive oxidative stress (ROS) is one of the main factors that cause dysregulation of bone maintenance process especially with regard to the physiology of osteoblast cells. ROS impairs the function of excretion or endocrine of osteoblast cells and inhibits the differentiation of progenitor cells and the calcification process. Lee et al. (2016) show that $\mathrm{H}_{2} \mathrm{O}_{2}$ reduced the expression of ALP, but the antioxidant properties of porcine placenta hydrolysates can overcome this problem (Lee et al., 2016; Terruzzi et al., 2019). Therefore, the antioxidant properties of mangosteen peel extract can reduce the amount of ROS created by the trauma of tooth extraction and result in increased expression of ALP by osteoblast cells compared to those of the control group.

The results of this research confirmed that the group with the highest expression of BMP-7 and ALP on days 7 and 30 was the one treated with a combination of DFDBBX and mangosteen peel extract. DFDBBX acted as a scaffold or lattice for the cells surrounding the defect to migrate and infiltrate the tooth socket via the graft, while also enhancing the differentiation of mesenchymal cells from osteoblast cells (Jamjoom and Cohen, 2015). Moreover, mangosteen peel extract contains isogarcinol that prevents inhibition of the osteogenic process caused by proinflammatory cytokines produced in response to the trauma of extraction. The xanthones ( $\alpha$-mangostin and $\gamma$-mangostin) and pectin in mangosteen peel extract also possess anti-inflammatory and antioxidant properties. The level of pectin contained in Indonesian mangosteen peel extract is the highest at $73.16 \%$. Wathoni et al. (2020) proved that pectin in Indonesian mangosteen peel extract can prevent stress in osteoblast cells and the impairing of osteoblast differentiation and functions. The combination of these properties in DFDBBX and mangosteen peel extract results in increased expression of BMP-7 and ALP as the number and differentiation of osteoblast are higher (Putri et al., 2017; Terruzzi et al., 2019; Wathoni et al., 2020).

\section{CONCLUSION}

This study shows that the application of a combination of DFDBBX and mangosteen peel extract (Garcinia mangostana) at $2 \%$ concentration increased the expression of BMP-7 and ALP in postextraction tooth sockets of C. cobaya on days 7 and 30 .

\section{ACKNOWLEDGMENTS}

None.

\section{AUTHORS' CONTRIBUTIONS}

All authors made substantial contributions to conception and design, acquisition of data, or analysis and interpretation of data; took part in drafting the article or revising it critically for important intellectual content; agreed to submit to the current journal; gave final approval of the version to be published; and agreed to be accountable for all aspects of the work. 

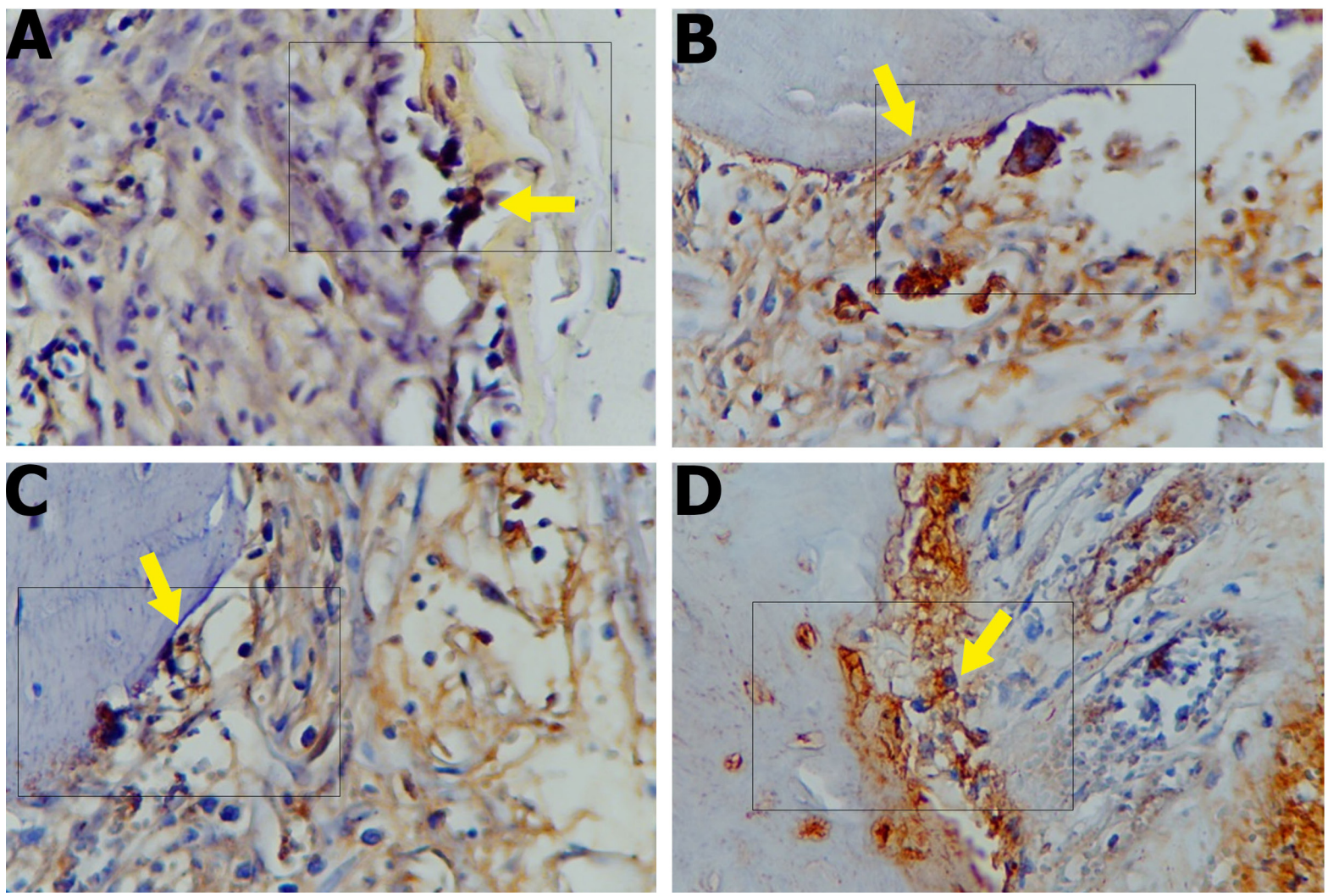

Figure 5. The expression of ALP on day 7 of (a) control group, (b) P1 group, (c) P2 group, and (d) P3 group was observed using a light microscope at 400× magnification. Osteoblast cells are indicated by an arrow showing the expression of ALP.
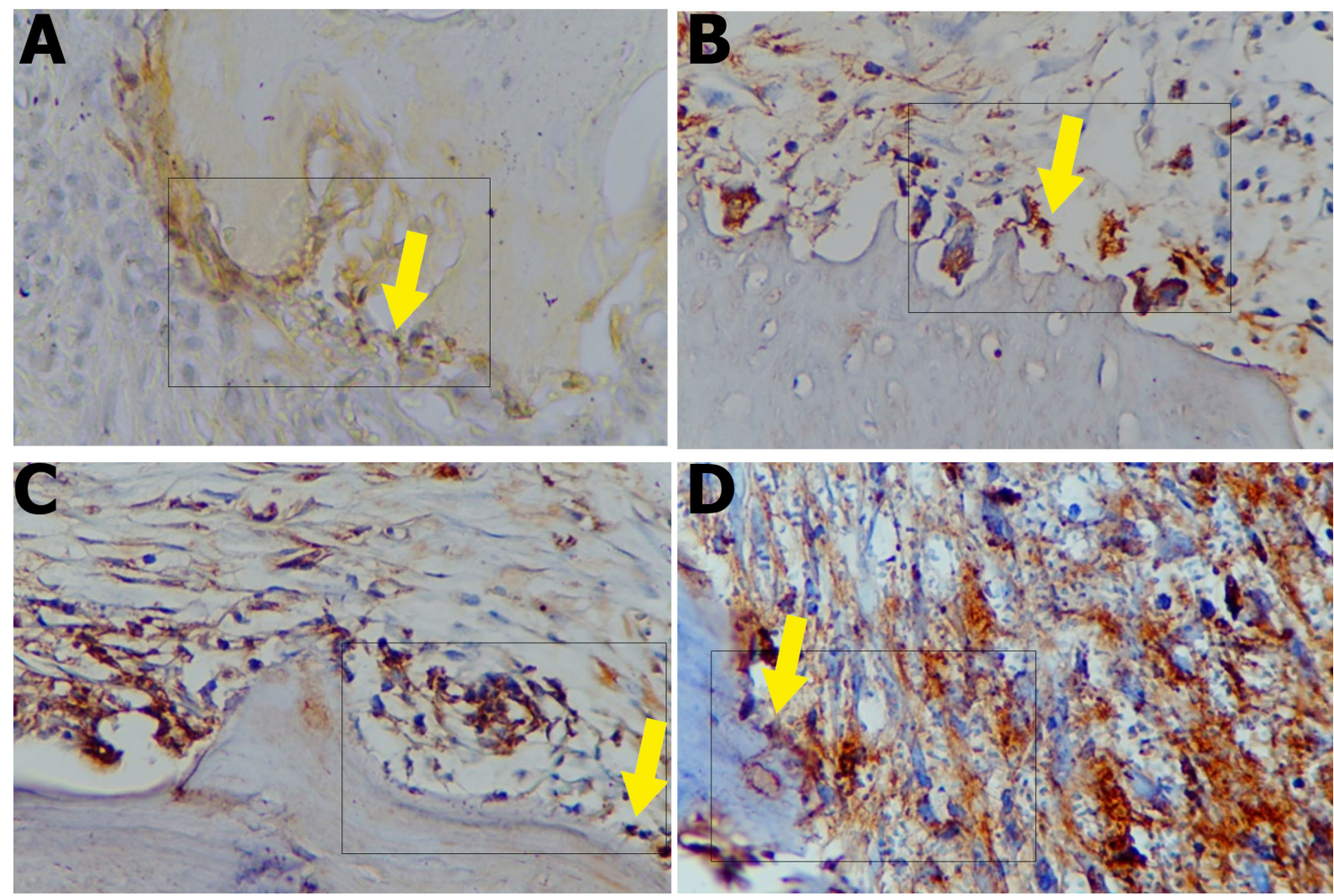

Figure 6. The expression of ALP on day 30 of (a) control group, (b) P1 group, (c) P2 group, and (d) P3 group was observed using a light microscope at $400 \times$ magnification. Osteoblast cells are indicated by an arrow showing the expression of ALP. 


\section{FUNDING}

There is no funding to report.

\section{CONFLICTS OF INTEREST}

The authors report no financial or any other conflicts of interest in this work.

\section{ETHICAL APPROVALS}

The ethical clearance was issued by the Health Research Ethical Clearance Commission with no. 420/HRECC.FODM/IX/2020.

\section{PUBLISHER'S NOTE}

This journal remains neutral with regard to jurisdictional claims in published institutional affiliation.

\section{REFERENCES}

Azhar IS, Kresnoadi U, Rahayu RP. Potency of Garcinia mangostana L peel extract combined with demineralized freeze-dried bovine bone xenograft on IL-1 $\beta$ expression, osteoblasts, and osteoclasts in alveolar bone. Dent J (Majalah Kedokt Gigi), 2018; 50:166-70; http://doi. org/10.20473/j.djmkg.v50.i3.p166-170

Bialy I El, Jiskoot W, Nejadnik MR. Formulation, delivery and stability of bone morphogenetic proteins for effective bone regeneration. Pharm Res, 2017; 34:1152-70; http://doi.org/10.1007/s11095-017-2147-x

Dunn CA, Jin Q, Taba MJ, Franceschi RT, Rutherford RB, Giannobile, William V. BMP gene delivery for alveolar bone engineering at dental implant defects. Bone Mol Ther, 2008; 11:294-9; http://doi. org/10.1038/jid.2014.371

Fu Y, Zhou H, Wang M, Cen J, Wei Q. Immune regulation and anti-inflammatory effects of isogarcinol extracted from Garcinia mangostana L. against collagen-induced arthritis. J Agric Food Chem, 2014; 62:4127-34

Giorgetti APO, César Neto JB, Ruiz KGS, Casati MZ, Sallum EA, Nociti FH. Cigarette smoke inhalation modulates gene expression in sites of bone healing: a study in rats. oral surgery. Oral Med Oral Pathol Oral Radiol Endodontol, 2010; 110:447-52; http://doi.org/10.1016/j. tripleo.2010.02.029

Jamjoom A, Cohen R. Grafts for ridge preservation. J Funct Biomater, 2015; 6:833-48; http://doi.org/10.3390/jfb6030833

Kresnoadi U, Ariani MD, Djulaeha E, Hendrijantini N. The potential of mangosteen (Garcinia mangostana) peel extract, combined with demineralized freeze-dried bovine bone xenograft, to reduce ridge resorption and alveolar bone regeneration in preserving the tooth extraction socket. J Indian Prosthodont Soc, 2017; 17:282-8; http://doi.org/10.4103/jips. jips_64_17

Kresnoadi U, Raharjo T, Rostiny R. Effects of mangosteen peel extract combined with demineralized freeze - dried bovine bone xenograft on osteocalcin, collagen 1 , and osteoblast as alveolar bone regeneration in socket preservation. J Indian Prosthodont Soc, 2018; 18:118-21

Kyun Kim Y, Fajardo KRR, O Valera AJ, Um IW. Autogenous tooth bone graft block for socket preservation: a one-stage technique. Dentistry, 2017; 07; http://doi.org/10.4172/2161-1122.1000414
Lee H, Chae H, Park S, Kim J. Porcine placenta hydrolysates enhance osteoblast differentiation through their antioxidant activity and effects on ER stress. BMC Complement Altern Med, 2016:1-10; http://doi. org/10.1186/s12906-016-1274-y

Lim YK, Yoo SY, Jang YY, Lee BC, Lee DS, Kook JK. Antiinflammatory and in vitro bone formation effects of Garcinia mangostana L. and propolis extracts. Food Sci Biotechnol, 2019; http://doi.org/10.1007/ s10068-019-00697-3

Osta B, Benedetti G, Miossec P. Classical and paradoxical effects of TNF- $\alpha$ on bone homeostasis. Forntiers Immunol, 2014; 5:1-9; http://doi.org/10.3389/fimmu.2014.00048

Pagni G, Pellegrini G, Giannobile W V., Rasperini G. Postextraction alveolar ridge preservation: biological basis and treatments Int J Dent, 2012a; 2012; http://doi.org/10.1155/2012/151030

Pagni G, Pellegrini G, Giannobile W V, Rasperini G. Postextraction alveolar ridge preservation: biological basis and treatments. Int J Dent, 2012b; 2012:151030; http://doi.org/10.1155/2012/151030

Paknejad Z, Jafari M, Nazeman P, Rad MR, Khojasteh A. Periodontal and peri-implant hard tissue regeneration. In: Tayebi L, Moharamzadeh K (ed.). Biomaterials for Oral and Dental Tissue Engineering, Woodhead, pp 405-28, 2017

Putri K, Darsono L, Mandalas H. Anti-inflammatory properties of mangosteen peel extract on the mice gingival inflammation healing process. Padjadjaran J Dent, 2017; 29:190-5; http://doi.org/10.24198/pjd. vol29no3.14399

Seppänen-kaijansinkko R. Tissue engineering in oral and maxillofacial surgery. Springer, Cham, Switzerland, 2019

Terruzzi I, Montesano A, Senesi P, Villa I, Ferraretto A, Bottani M, Vacante F, Spinello A, Bolamperti S, Luzi L, Rubinacci A. L-Carnitine reduces oxidative stress and promotes cells differentiation and bone matrix proteins expression in human osteoblast-like cells. Biomed Res Int, 2019; 2019

Titsinides S, Agrogiannis G, Karatzas T. Bone grafting materials in dentoalveolar reconstruction: a comprehensive review. Jpn Dent Sci Rev, 2019; 55:26-32; http://doi.org/10.1016/j.jdsr.2018.09.003

Venkataraman N, Bansal S, Bansal P, Narayan S. Dynamics of bone graft healing around implants. J Int Clin Dent Res Organ, 2015; 7:40; http://doi.org/10.4103/2231-0754.172930

Wathoni N, Yuan Shan C, Yi Shan W, Rostinawati T, Indradi RB, Pratiwi R, Muchtaridi M. Corrigendum to characterization and antioxidant activity of pectin from Indonesian mangosteen (Garcinia mangostana L.) Rind. Heliyon, 2020; 6; http://doi.org/10.1016/j.heliyon.2019.e03074

\section{How to cite this article:}

Kresnoadi U, Ruslianda DA, Laksono H. The potential for induction of the expression of bone morphogenetic protein-7 and alkaline phosphatase in postextraction tooth sockets using a combination of mangosteen peel extract and DFDBBX. J Appl Pharm Sci, 2022; 12(02):109-115. 